Rhode Island College

Digital Commons @ RIC

Master's Theses, Dissertations, Graduate

Master's Theses, Dissertations, Graduate Research and Major Papers Overview

Research and Major Papers

5-1-2013

\title{
Implementation of a Nurse-Driven Mobility Protocol in Critical Care
}

Kim M. Uustal

Rhode Island College

Follow this and additional works at: https://digitalcommons.ric.edu/etd

Part of the Nursing Commons

\section{Recommended Citation}

Uustal, Kim M., "Implementation of a Nurse-Driven Mobility Protocol in Critical Care" (2013). Master's

Theses, Dissertations, Graduate Research and Major Papers Overview. 226.

https://digitalcommons.ric.edu/etd/226

This Major Paper is brought to you for free and open access by the Master's Theses, Dissertations, Graduate Research and Major Papers at Digital Commons @ RIC. It has been accepted for inclusion in Master's Theses, Dissertations, Graduate Research and Major Papers Overview by an authorized administrator of Digital Commons @ RIC. For more information, please contact digitalcommons@ric.edu. 


\section{IMPLEMENTATION OF A NURSE-DRIVEN MOBILITY PROTOCOL IN CRITICAL CARE}

By

Kim M. Uustal

A Major Paper Submitted in Partial Fulfillment of the Requirements for the Degree of

Master of Science in Nursing

in

The School of Nursing

Rhode Island College

2013 


\begin{abstract}
Prolonged immobilization plays an important role in negative outcomes of critically ill patients. Immobility is widely documented in the literature as a cause of increased mortality and complications. Despite the growing evidence in support of early mobility, many ICUs are unable to effectively integrate early/progressive mobility into their daily practice. Literature supports early mobilization and physical therapy as a safe and effective intervention that can have a significant impact on functional outcomes. A progressive mobility tool may help to force a daily structured assessment of current mobility status, which supports the critical thinking process by the nurse and team to ensure effective and safe evaluation of the mobility level. The purpose of this project was to increase critical care nurses' understanding of the concept and benefits of early mobility during an educational program in which a nurse-driven progressive mobility protocol was introduced. Nurses were asked to voluntarily take a pre- and post- test surrounding the implementation of the protocol. Descriptive statistics were used to analyze study variables and differences between pre and post scores. Nurses' knowledge regarding mobility of critical care patients increased and $83.3 \%$ of nurses responding felt they provided earlier mobility.
\end{abstract}




\section{Table of Contents}

Background/Statement of the Problem.................................... 1

Literature Review....................................................... 5

Theoretical Framework...............................................23

Methods..................................................................26

Results............................................................. 35

Summary and Conclusions............................................. 38

Recommendations and Implications for Advanced Nursing Practice...........43

References......................................................45

Appendices............................................................. 50 


\section{Background/Statement of the Problem}

Nursing worldwide is refocusing on implementation of fundamental nursing care practices using the latest evidence to positively impact the most significant patient errors. These include injuries overall and injuries related to medications, health care acquired infections, pressure ulcers, failure to rescue, and falls. An important contributor to falls in hospitalized patients is immobility, which is linked to overall functional decline (Winkelman, 2009). Nurses need to refocus efforts to begin mobilizing patients as early as possible in the hospital stay. This fundamental of nursing care is essential to positive patient outcomes, as is the use of evidence-based practice to drive the transformation (Vollman, 2009).

Prolonged immobilization plays an important role in negative outcomes of critically ill patients. Bed rest reduces oxygen consumption and slows metabolism and is thus commonly recommended in critically ill adults to conserve energy and maintain the integrity of tubes and catheters (Winkelman, 2009). Although this effect may be desirable, the adverse effects of immobility far outweigh the positives (Winkelman). In healthy older adults, only 10 days of bed rest resulted in a 3.3 pound loss of lean body mass and a $15 \%$ loss of quadriceps strength. For the geriatric population, loss of even a small amount of muscle or strength may make the difference between going home and going to a nursing home (Milbrandt, 2008). After one week of bed rest, muscle strength may decrease as much as $20 \%$, with an additional $20 \%$ loss of remaining strength each subsequent week (Perme \& Chandrashekar, 2009). 
Immobility is widely documented in the literature as a cause of increased mortality and complications (Butcher, 2012). Intensive care unit (ICU) immobility can contribute to physical de-conditioning, increased ICU and hospital length of stay (LOS), and complications post discharge. Critically ill patients are often placed on strict bed rest and are sometimes completely immobilized by sedative and paralytic medications. Severe weakness has been recognized as a complication that may have profound and lasting consequences for patients and their caregivers (Fitzgibbon, 2012).

In 1947, Asher wrote, "Teach us to live that we may dread unnecessary time in bed. Get people up and we may save our patients from an early grave" (Asher, 1947, p. 968). Early mobility programs have been shown to result in greater ventilator free days, decreased incidence of ventilator acquired pneumonia (VAP), fewer skin injuries, decreased duration of delirium, and improved physical functioning before and after discharge from hospital (Bassett, Vollman, Brandwene, \& Murray, 2012). Mobility is also recognized as a very important factor in quality of life and psychological wellness (Vollman, 2010). Despite the growing evidence in support of early mobility, many ICUs are unable to effectively integrate early/progressive mobility into their daily practice (Timmerman, 2007). Because of competing priorities in busy critical care units and varying levels of nurses' knowledge and motivation, mobilizing patients out of bed is frequently delayed (Timmerman, 2007).

Literature supports early mobilization and physical therapy as a safe and effective intervention that can have a significant impact on functional outcomes (Morris et al., 2008). Numerous challenges need to be considered when mobilizing critically ill 
patients, including safety of tubes and lines, hemodynamic instability, personnel and equipment resources, sedation practices, the patient's size, the patient's pain and discomfort, and the time, valuing, and priority of mobilization. Safety in regard to the patient being able to tolerate the movement hermodynamically is probably the most significant factor (Vollman, 2010).

Current mobility practice on the ICU where the project took place requires manual repositioning every two hours, but this is often not done. Unless there is a doctor's order for out of bed, patients are usually confined to bed rest even if tubes and drains are removed. Passive range of motion is practiced randomly and infrequently. A lift team is available to assist with patient mobility throughout the hospital daily except after 4:00 PM on weekends and the overnight shift. The lift team members are frequently called to assist turning and repositioning critical care patients, and could easily be utilized to assist with mobility practices. When patients are mobilized, they are typically very weak and unable to tolerate much activity. Staff then becomes frustrated and further attempts for mobilization are put on hold.

Many patients were mobile and living normal lives prior to critical illness. It is the nurses' duty to preserve patients' quality of life and return them to maximum potential. Early mobility is a key factor in improving patient outcomes. Nurses need to implement protocols to support early mobility, and staff education in this area will enhance nursing skills in using mobility protocols. The purpose of this project was to implement a mobility program in the intensive care unit as well as increase nurses' understanding of the concept and benefits of early mobility. 
Next, the literature reviewed will be presented and discussed. 


\section{Literature Review}

Online searches were completed utilizing CINAHL, PubMed, Ovid, and MEDLINE; searches were limited to 2002-2012. Key words used were critically ill, physical mobility, bed rest adverse effects, hemodynamics, immobility complications, patient positioning, ICU's, and safety. Current literature was reviewed for evidence supporting the use and safety of progressive mobility protocols in the intensive care unit.

\section{Complications of Bedrest}

Allen, Glasziou, and DelMar (1999) performed a systematic review of the literature for evidence of benefit or harm of bed rest for any condition. They extracted 39 randomized controlled trials that examined the effect of bed rest on 15 different disorders. In 24 trials investigating bed rest following a medical procedure, no outcomes improved significantly and eight worsened in some procedures (lumbar puncture, spinal anesthesia, radiculography, and cardiac catheterization). In 15 trials investigating bed rest as the primary treatment, no outcomes improved significantly and nine worsened in some conditions (acute low back pain, labor, proteinuric hypertension during pregnancy, myocardial infarction, and acute infectious hepatitis). Results provided little support for bed rest as a form of management in a wide range of settings, and suggested that it may actually delay recovery and even harm the patient. One study within the review demonstrated that during an eight hour time frame, less than $3 \%$ of critically ill patients were turned in accordance with the standard practice of every two hours and close to $50 \%$ in the same time frame had little or no position change at all (Vollman, 2010). 
Bed rest, and the physical immobility associated with it, can cause serious complications. Cardiovascular effects include alterations in heart rate, orthostatic instability, and coagulopathy contributing to venous thromboembolic (VTE) events. Pulmonary complications of both atelectasis and aspiration are related to supine positioning and decreased respiratory excursion and stasis of secretions (Timmerman, 2007). Mechanical stress from both gravity and contractile muscle force is reduced or absent during bed rest, and muscle atrophy occurs in the absence of physical activity, leading to deconditioning (Winkelman, 2009). The absence of weight-bearing stress on the skeleton can result in bone demineralization and formation of urinary tract stones. Joint contractures, decubitus ulcers, delayed wound healing, insulin resistance, decreased GI motility, along with altered cognition and sleep patterns are also complications of bed rest (Timmerman, 2007).

The act of lying down shifts $11 \%$ of the total blood volume away from the legs, with most going to the chest. Within the first three days of bed rest, plasma volume is reduced $8 \%-10 \%$. The result is increased workload of the heart, elevating of resting heart rate, and a decrease stroke volume with a reduction in cardiac output. Orthostatic intolerance deteriorates quickly with immobility (Vollman, 2010). The heart muscle itself becomes deconditioned with bed rest. In healthy person, five days of bed rest result in insulin resistance and microvascular dysfunction. Immobilized patients are at greater risk for skin breakdown and delayed wound healing. The musculoskeletal system is severely affected by immobility and bed rest. Immobility in critically ill patients leads to decreased protein synthesis, increased catabolism of the muscle, and decreased muscle 
mass that is more pronounced in the lower limbs. The muscle atrophy that occurs in patients receiving mechanical ventilation can cause fatigue of the diaphragm and increase the challenge of weaning from the ventilator (Vollman).

Other respiratory challenges with bed rest include atelectasis and aspiration with supine positioning, with the greatest risk occurring when backrest elevation is less than 30 degrees. A supine position of less than 45 degrees is associated with decreased lung volume and increased airway resistance from direct compression of airways by blood volume (Winkelman, 2009). Many survivors of critical illnesses complain of weakness for months to years after discharge from the hospital (Brower, 2009).

The physiology and complications of bed rest in critical care are well understood. Intensive care unit-acquired weakness and functional dependency are recognized as unfortunate consequences of prolonged bed rest, long duration in ICU's, and mechanical ventilation. Further, sedative medications used to reduce metabolic demands also inhibit participation in exercise and activity (Adler \& Malone, 2012).

\section{Benefits of Mobility}

Early mobility can lead to positives outcomes including minimizing complications of bed rest, promoting improved function for patients, promoting weaning from ventilator as overall strength and endurance improve, reducing LOS, reducing overall cost, and improving quality of life (Perme \& Chandrashekar, 2009). In the early 1970's, techniques were described for augmenting ventilation during ambulation utilizing a walker that could accommodate a ventilator, oxygen, and intravenous catheters. A bench was also attached so the patient could sit and rest. It was stated that providing 
early ambulation for patients receiving mechanical ventilation facilitated weaning from ventilator support and minimized problems associated with prolonged bed rest (Perme \& Chandrashekar).

Mundy et al. (2003) conducted a randomized control trial on early mobilization of patients hospitalized with community-acquired pneumonia (CAP) to determine if mobilization could reduce hospital LOS. Four hundred and fifty-eight patients with CAP admitted to 17 general medical units were randomized into either an intervention group $(n=227)$ or a usual-care $(n=231)$ group. Groups were similar terms of age, gender, disease severity, door-to-drug delivery time, and IV-to-PO switchover time. The intervention group received mobility, defined as sitting out of bed or ambulating for at least 20 minutes during the first 24 hours of hospitalization, with progressive mobilization occurring each subsequent day during hospitalization. Hospital LOS for the early mobility group was significantly less (mean=5.8 vs. 6.9 days; adjusted absolute difference, 1.1 days; $95 \%$ CI 0.0 to 2.2 days). The study concluded that hospital LOS was reduced without increasing the risk of adverse outcomes.

The benefit of early mobility in critically ill patients was demonstrated in a study by Schweikert and colleagues (2009). Subjects were those who had received mechanical ventilation for $<72$ hours, were functionally independent prior to hospitalization, and were expected to continue for at least 24 hours after enrollment. Patients were randomized to receive either early exercise and mobilization (physical therapy and occupational therapy) during periods of daily interruption of sedation $(n=49)$ or daily interruption of sedation with therapy as ordered by the primary care team $(n=55)$. Both 
groups were managed by goal-directed sedation and underwent daily interruption of sedation. The primary endpoint was the number of patients returning to independent functional status at hospital discharge, defined as the ability to perform six activities of daily living and the ability to walk independently. Secondary endpoints included duration of delirium and ventilator-free days during the first 28 days of hospital stay. Patients in the intervention group vs. control group had significantly shorter duration of delirium (median 2 days vs. 4 days; $\mathrm{p}=0.02$ ) and more ventilator free days (23.5 days vs. 21.1 days; $p=0.05$ ) during the 28-day follow-up period than did control patients (Schweickert et al. 2009).

Exercise in critically ill patients is able to alter inflammatory markers known as interleukin 6 (IL-6) and interleukin 10 (IL-10), which act at a systemic level to decrease proteolysis, which leads to muscle wasting. Low intensity physical activity produces a trend in decreasing IL-6 (proinflammatory cytokines) and increasing IL-10 (antiinflammatory cytokines), promoting a recovery phase. It is possible that myopathy in sepsis syndromes may be prevented, however further studies in this area must be conducted (Paratz \& Kayambu, 2011).

\section{Safety and Feasibility of Early Mobility}

Mobilizing patients in the intensive care environment is not without risk.

Catheters and supportive equipment attached to patients can become dislodged and cause injury. Mobilizing can cause unwanted stress and pain for patients and families, and critically ill patients with physiological derangements can have adverse hemodynamic responses to activity (Adler, 2012). The ability to mobilize patients is closely connected 
to sedation management. Many critical care patients are oversedated due to clinician fears that agitated patients will pull their tubes out or concerns about patient comfort. The mobility protocols researched did not specify sedation levels, but a patient must be responsive to participate. Sedation levels, therefore, must be minimized to allow patients to respond to stimuli (AHRQ, 2009).

The benefits of early mobility are critical to improved patient outcomes. In a prospective cohort study, Bailey et al. (2007) focused on the feasibility and safety of an early ambulation intervention in 103 patients on mechanical ventilation for $>4$ days who were admitted to a Respiratory ICU. Early activity began when the patient met neurologic (responds to verbal stimulation), respiratory $(\mathrm{FiO} 2<0.6, \mathrm{PEEP}<10 \mathrm{~cm} \mathrm{H} 2 \mathrm{O}$ ) and circulatory (no catecholamine drips) criteria. The goal was to enable patients to walk $>100$ feet at RICU discharge. Of 1,499 recorded activity events, over 50\% were ambulation events. At RICU discharge, patients were able to walk $212 \pm 178$ feet. A majority of survivors $(69 \%)$ were able to walk $>100$ feet at discharge. Walk distance appeared to influence placement upon discharge. Those discharged home were able to walk further distances (median=400 feet) compared to those discharged to skilled nursing facilities (median=270 feet) and long-term acute care facilities (median=140 feet). This study provided details on feasibility and safety of initiating mobility interventions in an early stage of critical illness. The study also reported that the multidisciplinary team was able to conduct the mobility intervention without staffing increases (Bailey et al., 2007). Further research is indicated. 
Adler and Malone (2012) performed a systematic review of early mobilization in the intensive care unit. Their purpose was to evaluate the literature related to mobilization of the critically ill patient with an emphasis on functional outcomes and safety. Fifteen studies were included based on Sackett's Level of Evidence. Studies included both prospective and retrospective designs, with randomization occurring in just 3 studies. Ten studies examined cohort populations or samples of convenience. Eleven of those studies were prospective. Four studies were retrospective analyses. The studies were categorized into two groups based on safety and functional outcomes. Functional outcomes were further divided into three areas: muscle strength; functional mobility; and quality of life. Improvement in functional mobility following early and progressive physical therapy in the ICU was documented, but limited by the fact that the measurement outcomes were not uniform across the studies. Variability of outcomes measures included acquisition of mobility milestones, the Functional Status Score in the ICU (FSS-ICU), the Functional Independence Measurement (FIM), and the Barthel Index. Mobility milestones (e.g. time to first out of bed, standing) were reached earlier in the intervention groups than the comparison groups in four of the other studies. Compared to controls, ambulation frequency was greater in one study, and ambulation distance was greater at time of hospital discharge in two studies. Objective measures such as the Barthel Index and FIM improved in the intervention groups at time of discharge in another study. Bed mobility and transfers were improved in three studies.

Untoward events occurred in $\leq 4 \%$ of total patient interactions. The reviewed studies used specific physiologic responses and patient complaints to initiate and 
terminate exercise or activity sessions. In the category of safety/untoward events, there were 14 activity-associated untoward events during 1449 activity sessions, none of which were classified as serious. The most commonly cited adverse event was oxygen desaturation. Related to adverse events, accidental removal of patient support equipment happened rarely $(<1 \%)$. Early mobilization and physical therapy were identified as a safe and effective intervention that can have significant impact on functional outcomes. The authors indicated that critically ill patients can safely exercise, sit up, transfer to chair, and ambulate in hallways; however, few studies of randomized and controlled interventions have been published (Adler \& Malone, 2012).

Clark et al. conducted a retrospective cohort study in 2012 to assess the effects of an early mobilization protocol on complication rates, ventilator days, and ICU and hospital LOS for patients admitted to a trauma and burn ICU (TBICU). Pre- and postearly mobility program patient data from admissions to the TBICU between May 2008 and April 2009 were compared. No adverse events were reported in the risk management system for the patients during a mobility event in either time period. Although overall hospital LOS was significantly shorter (2.4 days) in the post-early mobility program group ( $\mathrm{p}=0.02$ ), when adjusted for injury and severity score (ISS), the hospital LOS was not statistically significant. There were no differences in mechanical ventilation days, mortality, and discharge disposition. Patients were less likely to have pneumonia, airway, pulmonary, or vascular complications post mobility program, as evidenced by calculated risk ratios (RR) and 95\% confidence intervals (CI) for the association between 
early mobility and complication occurrence. Overall, early mobilization of patients in a TBICU was safe and effective.

The question of feasibility and safety of early mobility in critical care may be answered through the use of protocolled mobility interventions with daily assessments for specific inclusion and exclusion criteria (Ross \& Morris, 2010).

\section{Use of Mobility Protocols}

Reducing costs for patients requiring long-term mechanical ventilation led to an interest in developing different care delivery models. Hopkins, Spuhler, and Thomsen (2007) researched and implemented a respiratory care process model with a goal of transforming the Respiratory Intensive Care Unit (RICU) culture, and that included an early mobility protocol. A side benefit of their project was the simultaneous development of a culture of safety and teamwork. The protocol included the physical therapist, respiratory therapist, nurse, and critical care technician working as a team. Activities began with sitting on the edge of the bed without back support, then sitting in a chair after transfer from the hospital bed, and finally ambulating with, and then without, assistance using a walker or support from the RICU staff. Following implementation of the early mobility protocol in the RICU, the mean ICU and hospital LOS for respiratory failure patients declined from 13 days in 2000 to 10 days in 2005. In the same timeframe, performance of tracheostomy declined from 29\% in 2000 to less than 5\% in 2005 and weaning failure declined from $12 \%$ in 2000 to $3 \%$ in 2005 . According to the authors, early activity along with sedation and mechanical ventilation management were likely the contributors to this success. 
Morris et al. (2008) conducted a prospective cohort study in a university medical intensive care unit that assessed whether a mobility protocol increased the proportion of intensive care unit patients receiving physical therapy vs. usual care. A total of 330 patients were enrolled, with 165 each in the protocol and the usual care groups. The protocol was initiated within 48 hours of mechanical ventilation and consisted of four levels of increasing activity, from passive range of motion through active transfer to chair (out of bed). It safely increased the proportion of acute respiratory failure patients who received PT without adverse events and without increasing cost. Protocol patients were out of bed several days earlier (5 vs. 11 days, $\mathrm{p} \leq .001$ ) and spent fewer days in the ICU (length of stay 5.5 vs. 6.9 days for usual care, $\mathrm{p}=.025$ ) and the hospital (LOS 11.2 vs. 14.5 days for usual care; $p=.006$ ). The cost savings associated with shorter LOS in the ICU and the hospital more than paid for the entire cost of the mobility team.

In a follow up study, Morris et al. (2011) assessed a cohort of 280 survivors, all of whom required mechanical ventilation for acute respiratory failure during their hospitalization, to determine if early mobility during an ICU admission was a predictor of improved outcomes. Of the 280 survivors, status at one year following hospitalization was confirmed for 258. Survivors of ARF who required mechanical ventilation were often readmitted to the hospital and had a one-year mortality rate of $17 \%(44 / 258)$ after hospital discharge. Four variables predicted hospital readmission or death, including tracheostomy, female gender, lack of early ICU mobility, and Charlson Comorbidity Index. Patients not in the early mobility therapy group had higher odds of readmission or death $(\mathrm{p}=0.0362)$. Other outcomes that were statistically significant included decreased 
ventilator days ( $\mathrm{p}=0.0250)$, days in bed $(0.0008)$, decreased ICU length of stay $(p=0.0070)$, decreased hospital length of stay $(0.0010)$. The strengths of this study were that the follow- up design identified predictors of 12-month readmission or death. Conclusions indicated that early ICU mobility protocols represent a potentially modifiable in-patient variable that may improve outcomes (Morris et al., 2011).

Another study by Bassett, Vollman, Brandewene and Murray (2012) focused on integrating a multi-disciplinary mobility program into intensive care practice. This multicenter ICU collaborative included 13 ICU's in eight hospitals with in the US. It focused on an initiative to integrate the latest evidence on mobility practice into current ICU culture. Emphasis was placed on frontline caregiver empowerment to drive mobility using an evidence-based guide. The progressive mobility tool helped to force a daily structured assessment of current mobility status, which supported the critical thinking process by the nurse and team to ensure effective and safe evaluation of the mobility level. To support and sustain the implementation process, mechanisms including coaching calls and various change interventions were offered to modify staffs' behavior. Several tools were identified and adapted for use, such as a progressive mobility continuum, an organizational development tool for staff learning, and a direct observation data collection tool. In addition to improving early mobility, it also yielded improvements in team dynamics and culture within the ICU. Quantitative data on ventilator days and timing of physical therapy consultation were measured. There were no significant differences demonstrated in any of the mobility intervention group measurements. However, a reduction in ventilator days (3 days pre vs. 2.1 days post) 
approached significance ( $\mathrm{p}=0.06$ ) (Bassett et al., 2012). The progressive mobility tool helped to force a daily structured assessment of current mobility status.

According to the authors, this was the first attempt at a multi-center improvement collaborative on early mobility. Data were collected at each participant site by hospital staff. Specific data collection instructions were provided and discussed on conference calls, but there was no additional training or a designated data collector which may have resulted in inconsistent or inaccurate data. Lack of inclusion of severity of illness or patient diagnosis limited the authors' ability to measure the effect of acuity on overall status. This collaborative effort provided teams with key information on understanding the impact of early ICU mobility and the opportunities to change practice within their units (Bassett et al).

Drolet et al. (2013) conducted a quasi-experimental design study that used a before and after intervention to implement a mobility order set with a daily protocol. The purpose of the study was to determine the effectiveness of a nurse-driven mobility protocol to increase the percentage of patients ambulating during the first 72 hours of the hospital stay. The study took place in a 16-bed adult medical/surgical intensive care (ICU) and a 26-bed adult intermediate care unit (IMCU) at a large community hospital. A multidisciplinary team developed and implemented a mobility order set embedded with an algorithm to guide nursing assessment of mobility potential. Based on the assessments, the protocol empowered the nurse to consult physical therapists or occupational therapists when appropriate. Daily ambulation status reports were reviewed each morning to determine each patient's activity level. Retrospective and prospective 
chart reviews were performed to evaluate the effectiveness of the protocol for patients 18 years of age and older who were hospitalized 72 hours or longer.

In the 3 months prior to implementation of the nurse-driven mobility protocol, $6.2 \%$ (12 of 93) of the ICU patients and 15.5\% (54 of 349) of the IMCU patients ambulated during the first 72 hours of their hospitalization. During the 6 months following implementation, those rates rose to $20.2 \%$ ( 86 of 426 ) and $71.8 \%$ (257 of 358), respectively. This experience with a nurse-driven mobility protocol suggested that the frequency of patient ambulation in an adult ICU and IMCU during the first 72 hours of a hospital stay can be increased. The Drolet et al. study not only increased ambulation of patients but also demonstrated the importance of the nurse's role in promoting mobility. While the benefits, safety, and feasibility of early mobility have been demonstrated, the challenge remains for advanced practice nurse to educate the ICU staff and promote the culture to one of early activity and mobility.

\section{Promoting Nursing Practice Change Using Mobility Protocols}

Mobilizing patients is a central nursing action that has been lost in the high acuity environment. Skill in basic nursing actions are learned in school and transformed into adequate performance in the clinical setting. The performance of practical skills in nursing is characterized by complexity on many levels. While mobilization is part of the beginning nursing skills that are taught, its importance is often overlooked. More complex procedures and technological interventions often seem to become the focus of care, yet basic interventions such as early mobilization have been found to significantly improve patient outcomes. The complexity lies in sequencing the substantial elements in 
relation to the individual patient's condition and needs (Bjork \& Kirkevold, 2000). For the nurse educator, these complexities must be considered for effective education and implementation.

Tran, Stone, Fernandez, Griffiths, and Johnson (2009) examined the effectiveness of implementation of clinical practice guidelines on nurses screening patients for alcohol abuse. While this was not a study related to early mobility, it does discuss the factors related to changing practice through use of a protocol and guidelines. Factors were identified that limited the effectiveness of the clinical practice guideline, including design of the education program, existing level of knowledge and competence, and strategies in place to ensure sustainability of the program. The authors suggested that the readiness of the nurses to adopt guidelines into practice prior to implementation of the guideline was a critical factor in the subsequent change in practice. Sustainability of a policy implementation may require considerable structured processes for it to become integrated into normal practice (Tran et al. (2009). This study highlighted the difficulties of introducing and sustaining change amongst health professionals.

Overton, McCalister, Kelly and Macvicar (2009) focused on Practiced-based Small Group Learning (PBGSL) to examine the process of implementing change in practice. The participants' commitment to change was recorded in a log-sheet that groups completed after their discussions. The participants were then interviewed five to six months following the first meeting and questioned regarding their intended changes to clinical practice, factors that influenced the adoption of changes, and the types and processes of implementing changes. Strategies for change indicated that receiving new 
information appeared to influence nearly all decisions to introduce change in clinical practice. For some, small group discussions were helpful to their decision to introduce practice change (Overton, McCalister, Kelly, \& Macvicar, 2009). When implementation of a specific change was within the control of the participants, they seemed motivated primarily by a desire to improve their practice (Overton, McCalister, Kelly, \& Macvicar, 2009).

Mobility is a critical part of nursing practice. Nurses often depend on physical therapy to do even the simplest of mobility tasks, such as range of motion. However, they are not regularly available. In a survey of 984 physical therapists in the United States (US), it was found that only $10 \%$ of ICU's had physical therapists assigned to work in the ICU (Hopkins \& Spuhler, 2009). This fact accentuates the need for a nursedriven mobility protocol. Other resources are not readily available, but more importantly, mobility is central part of the nurse's role. The need to increase knowledge and change nursing practice in relation to early mobility is a key role for the advanced practice nurse.

Barriers to the promotion of early mobility include clinicians' knowledge deficits, sedation practices, lack of human and equipment resources, patient physiologic instability, and established ICU culture. Altering well-established routines and patterns of care requires a comprehensive approach to instituting not only individual behavior change, but also a system that support a shift in group norms (Bassett et al., 2012). While literature supports evidence of improved outcomes with early mobility, changes in practice can present challenges. Winkelman and Peereboom (2010) performed a descriptive study examining the nurses' perceptions of the barriers to and 
facilitators of progressive mobility. Data were collected in a semi-structured interview conducted with 33 nurses prior to implementing any patient activity related to mobility. The goal of the interview was to determine the nurses' perception related to patient readiness or inability to increase mobility activities. Of 49 activities identified by nurses during the interview, 41 were limited to in-bed activity, including frequent manual turning or passive range of motion exercises. Only one nurse planned active range of motion exercises. Unstable vital signs and low respiratory tolerance were the common reasons for restricting activity. Safety concerns (fear of patient falling or risk to tubing or catheter integrity) were cited in $34 \%$ of the interviews. Eleven nurses ( $27 \%$ of interviews) reported sedation to be an important barrier to out of bed activity. The nurses did not cite physicians' orders as either a barrier or facilitator.

When periods before and after the protocol were compared, an association was apparent between the presence of the protocol and planned out-of-bed activity. During implementation and evaluation of the protocol, out-of-bed activity increased and occurred on day 6 compared with day 9 among patients with long ICU stays. Another factor correlated with out-of-bed activity was a score of 10 or greater on the Glasgow Coma Scale. Limitations included that study was done at a single institution with a convenience sample. In addition, the design did not examine whether the protocol caused a change in nursing behavior. However, this study does provide unique data about nurses' perceptions of patients' readiness for mobility activity and how assessment is linked to progression of mobility in the ICU. The authors suggested that the presence of a protocol 
could act as a facilitator in implementing progressive mobility (Winkelman \& Peereboom, 2010).

Changing practice to an evidence-based perspective must have essential components in place for implementation. Support from hospital administrators, available resources, strong unit-based clinical leadership, mentoring, and feedback are some of these essential components. Clinical experts must be in place to guide and mentor staff from the identification of a practice issue to the channeling of those ideas that will ultimately improve patients' outcomes. Staff who identify the problem are often committed to solving the issue and are determined to change practice (Lusardi, 2012). Barriers encountered at individual and organizational levels hinder clinical nurses in their ability to deliver evidence-based practice. Advanced practice nurses act as knowledge brokers in promoting EBP among clinical nurses. Advanced practice nurses promote the uptake of evidence by developing the knowledge and skills of clinical nurses through role-modeling, teaching, clinical problem solving and facilitating change (Gerrish et al., 2011).

In summary, the research supports implementation of progressive mobility protocols. The safety, feasibility, and impact on functional outcomes has been supported in multiple studies and reviews of the literature. While the focus in critical care has been on disease diagnosis and highly technological treatment, nursing must commit to reclaiming the fundamentals of nursing care that are essential to positive outcomes and use evidence-based practice to drive the transformation (Vollman, 2009). Protocols and training in early mobility should help increase knowledge to promote incorporation of 
early mobility into patient care. Staff education on the complications of immobility may lead to an increase of ICU mobility within patient care activities (Ross \& Morris, 2010). Next, the theoretical framework guiding this project will be described. 


\section{Theoretical Frameworks}

Lewin's Change Theory was chosen to guide the development and implementation of a nurse-driven progressive mobility protocol. Kurt Lewin described a method that provides a basis for considering the process of planned change (Lewin, 1951). Planned change occurs by design, as opposed to change that is spontaneous or that occurs by accident. Effective change can be implemented with using this theory (McEwen \& Wills, 2007).

The concepts of field and force are central to Lewin's ideas. A field is viewed as a system, so when change occurs in one part or aspect of the system, the whole system must be examined. Force is defined as a directed entity that has the characteristics of direction, focus, and strength. Change is a move from the status quo that results in disruption of the balance of forces (McEwen \& Wills, 2007).

There are two forces involved in change, driving forces and restraining forces. A driving force encourages or facilitates movement to a new direction, goal, or outcome and causes a shift in equilibrium towards change. A restraining force blocks or impedes progress toward the goal and causes a shift in equilibrium, which opposes change and counters driving forces (Lewin, 1951).

Adequate project planning included analysis of these opposing forces. Driving forces must be identified and accentuated (Lewin, 1951). Driving forces identified in this project included support of administration and management, an educational program for nursing, and evidence-based literature supporting mobility of critically ill patients. Restraining forces must be identified and minimized. Some of the restraining forces 
identified were nurse reluctance to mobilize patient for fear of unplanned extubation or hemodynamic instability. Oversedation, delirium, resistance to change, time constraints, and lack of specific protocols addressing mobility are other barriers identified as restraining forces. Effective change is the return to equilibrium as a result of balancing opposing forces (McEwen \& Wills, 2007).

Lewin identified three phases that must occur if planned change is to be successful: unfreezing the status quo; moving to a new state or change; and refreezing the change to make it permanent (McEwen \& Wills, 2007). Unfreezing is the process which involves finding a method of making it possible for people to let go of an old pattern or habit that was counterproductive in some way (Lewin, 1951). Change can be stressful and cause uneasiness, resistance, and loss of control. Individuals involved must be informed of the need for change and should agree that the change is needed. Unfreezing can be achieved by increasing the driving forces and decreasing the restraining forces that negatively affect the movement toward change. The next step is moving to a new level or changing. The initiator of the change should recognize that change takes time and should be thoughtfully and comprehensively planned before implementation. Refreezing is establishing the change as a new habit, so that it now becomes standard operating procedure. Without this stage of refreezing, it is easy to go back to the old ways (Kritsonis, 2005). Stabilization occurs and the change is assimilated into the system.

The usual practice in the ICU had been complete bed rest for the majority of critical care patients. Even if there was not an order for any activity, it was generally 
assumed by nurses that the patient was on bed rest. The use of Lewin's planned change theory to implement a nurse-driven mobility protocol will allow a better understanding and plan for implementation. Due to the variety of medical and surgical patients in this ICU, a detailed education program and protocol needed to be developed. The integration of best evidence and education regarding the complications of bed rest prior to implementation would be part of the unfreezing stage. Integration of the mobility protocol into daily practice at the bedside would be part of the change phase. Altering well-established routines and patterns of care requires a comprehensive approach to instituting not only individual behavior change but also a systems change (Bassett, Vollman, Brandwene, \& Murray, 2012). Implementation of a nurse-driven protocol in the ICU can be very challenging but it was believed that the use of the theory would assist in the process.

The Logic Model for Program Development (Appendix A) was used to guide implementation of the mobility protocol and the nurses' education (University of Wisconsin-Extension Program Development and Evaluation, n.d.).

The Logic Model is useful in program planning because it helps to plan with the end in mind. Resources are used in processes in order to accomplish the program's desired results, which are expressed in terms of desired outputs, outcomes, and the program's impact (Longest, 2005). In the proposed project, nursing knowledge of the benefits and use of early mobility in critical care was measured. Long-term outcomes included changes in nursing care to include mobility implementation and evaluation into daily care. The Logic Model will be discussed in detail in the methods section. 


\section{Methods}

\section{Application of the Logic Model}

The Logic Model, obtained from the University of Wisconsin Cooperative Extension, framed the educational programs' investments to results (Appendix A). Components of the Logic Model include situation, inputs, outputs, outcomes, and impact. Inputs represent the problem description gathered from existing data, staff input, and leadership expert opinion. Key stakeholders are identified and committed to achieving success in the educational program design. Inputs reflect the available resources, while outputs are program activities. The outcomes are results, such as knowledge gains, which yield an impact, or the lasting improvement in nursing practice or patient outcomes.

For purposes of this project, the situation was that nursing knowledge regarding mobilizing critically ill patients was lacking. Education related to the benefits, feasibility, and safety of mobilization, using a protocol, would need to be developed. Implementation of a protocol for mobilization would provide critical care staff guidelines for mobility. Inputs are defined as what we invest into the program, including resources and contributions that go into the program. Administrative support is included because without this factor the program could not move forward. Administrative support was available as identified through the institution's established Mobility Task Force. Administration must be willing to allow investment of time and resources for the program to be successful. Other inputs included staff support and education, time commitments for education and voluntary participation in pre- and post-tests, and the hospital-wide mobility committee input and support. 
Outputs describe the activities and participation of the targeted population. The activities in this program included the voluntary pre- test for staff. The education portion of the program was delivered by poster presentation during the annual critical care competency fair. Then, and over a four week time period, the mobility protocol, which was identified from the literature, was formally incorporated. After that four week time period, nursing staff voluntarily completed a post-test to evaluate their knowledge of mobility practices. Other activities were the use of laminated reference cards outlining the protocol, mentoring by the author and nurse champions, and informal surveillance of implementation of the mobility protocol. Outcomes are the results or changes for individuals, groups, communities, organizations, or systems that are impacted by the program. The short term outcomes in this project included potentially increased knowledge of critical care nursing staff in all aspects of progressive mobility. It was anticipated that nurses' increased understanding would increase their confidence and also motivation to get patients moving earlier and more frequently. Informal monitoring and surveillance by the researcher anecdotally represented the medium phase of outcomes. The potential long term outcomes or impact would be: consistent incorporation of mobility activities into patient care; increased empowerment of critical care staff in decision-making regarding patient mobility, therefore increasing the standard of care for the critical care unit; and ultimately improved patient outcomes. Measurements of the long-term outcomes are beyond the scope of this project.

Some assumptions made for this program included the potential eagerness of staff to learn a new practice routine, and the willingness of nursing staff to participate in the 
pre- and post-testing. Physicians, physical therapy, and patient/family cooperation and support must also be considered for implementation to be successful. The assumption that hospital administration supported the mobility project was a key factor in going forward. Introduction of any new policy or procedure needs to have the support of administration due to fact that time and sometimes money must be included for any project to move forward. Another assumption was the protocol would be easily understood by all involved and reasonable to implement.

External factors include the environment in which the program exists and the external factors that interact with and influence the program action. When any new program is introduced into a setting, there are usually a few members that will resist the change. Lack of human and equipment resources, patients' physiologic instability, sedation practices, staff knowledge deficits, and limited time factor for training are all factors that may present barriers to implementation of the protocol.

\section{Needs Assessment}

Prior to the initiation of the project, several informal discussion groups within the ICU identified a need for earlier mobility of patients. The inter-disciplinary team, during daily rounds in the ICU, began discussing the need for earlier mobility for improved patient outcomes. This discussion was carried over to the ICU nursing staff meetings. In response to a growing concern from the medical team and nursing clinical managers regarding the need for improved mobility practices, a hospital-wide Mobility Task Force was established. 
One of the goals agreed upon by the Task Force was to increase nursing knowledge related to the benefits of mobility and the practice of implementing early mobility in critically ill patients. This author was asked by the Task Force to review the literature and identify a progressive mobility protocol that was feasible for use in the ICU. The protocol developed by Morris et al. (2008) was reviewed and approved by the committee in October 2012.

\section{Program Content, Outline, and Objectives}

The desired outcome for this project was increased knowledge of early mobility and implementation of a mobility protocol for critical care patients. Transformation of the practice of the ICU to one of promotion of early mobility as part of recovery and bringing it to the foreground was the main goal. The content outline of the educational program was developed from the needs assessment, literature review of early mobility and protocols, committee discussion, and personal experience. Program content and objectives are illustrated in Table 1.

\section{Program Implementation}

Purpose. The purpose of this project was to increase critical care nurses' understanding of the concept and benefits of early mobility. A nurse-driven progressive mobility protocol developed by Morris et al. (2008) was introduced during an educational program. Additions to the protocol were instituted to target the specific teams involved, such as adding the lift team utilized by the ICU in the study.

Design. This project used a pre- and post-test design. The intervention was the nursing education program. 


\begin{tabular}{|l|l|}
\hline \multicolumn{2}{|l|}{ Table 1.} \\
Program Content and Objectives & Program Objectives \\
\hline Program Content & $\begin{array}{l}\text { Describe the benefits of early mobility in } \\
\text { critical care. }\end{array}$ \\
\hline Benefits of mobility in critical care patients & $\begin{array}{l}\text { Identify the risks associated with bed rest } \\
\text { and immobility in ICU patients. }\end{array}$ \\
\hline Risks to prolonged immobilization & $\begin{array}{l}\text { Discuss challenges and barriers to making } \\
\text { positioning and mobility of patients a } \\
\text { priority of practice in the ICU. } \\
\text { Discuss safety and feasibility. }\end{array}$ \\
\hline $\begin{array}{l}\text { Exclusions and reasons to terminate } \\
\text { mobility } \\
\text { mobility protocol }\end{array}$ & $\begin{array}{l}\text { Describe the process of progressive } \\
\text { mobility and advantages of protocol use. }\end{array}$ \\
\hline Progressive mobility protocol algorithm
\end{tabular}

Sample. The sample included ICU nursing staff from all shifts. All staff RN's in the ICU were eligible.

Site. This project took place at a $300+$ bed regional hospital located in New England. Services range from obstetrics, orthopedics, cardiac telemetry, cardiac catheterization, oncology, interventional radiology, hyperbaric to rehabilitative medicine. The study site is a teaching facility with emergency medicine and family practice residency programs. The hospital contains one ICU, which is staffed by five intensivists. The ICU utilized in this project was a 15 bed medical-surgical unit with a nurse to patient ratio of $1: 2$.

\section{Procedures}

Permission for this project was obtained from the Vice President of Patient Care Services, who is also the chairman of the hospital-wide mobility committee. Permission 
was also obtained from the critical care physicians and immediate supervisors. Prior to beginning this project, IRB approval was obtained from the Rhode Island College IRB and the hospital IRB.

The project was an initiative to integrate the latest evidence on mobility practice into current ICU practice. The intent of the protocol was to provide a structured approach for the nursing staff to evaluate and progress patient activity in a stepwise fashion. The protocol would help nurses view mobility as a core component of nursing care and empower them to proactively initiate therapeutic patient activity (Timmerman, 2007).

A protocol for progressive mobility developed by Morris et al. was chosen from the review of the literature (Figure 1.). The protocol was presented to the Task Force for review and was accepted. The protocol had been implemented in many different critical care units and had been adapted be various institutions as needed. For purposes of this study, members of the lift team were included in the protocol as a resource.

The protocol consists of four steps that are easy to follow and can be utilized quickly and easily by staff. Nurses were instructed that the protocol was to be used as a tool to help determine readiness and promote early mobility and that these assessment should take place at least twice daily. If a patient was not ready for mobility early in the day, they might meet the criteria later in the day. The goal was for nurses to attempt, through assessment via the protocol, to get patients mobilizing. 


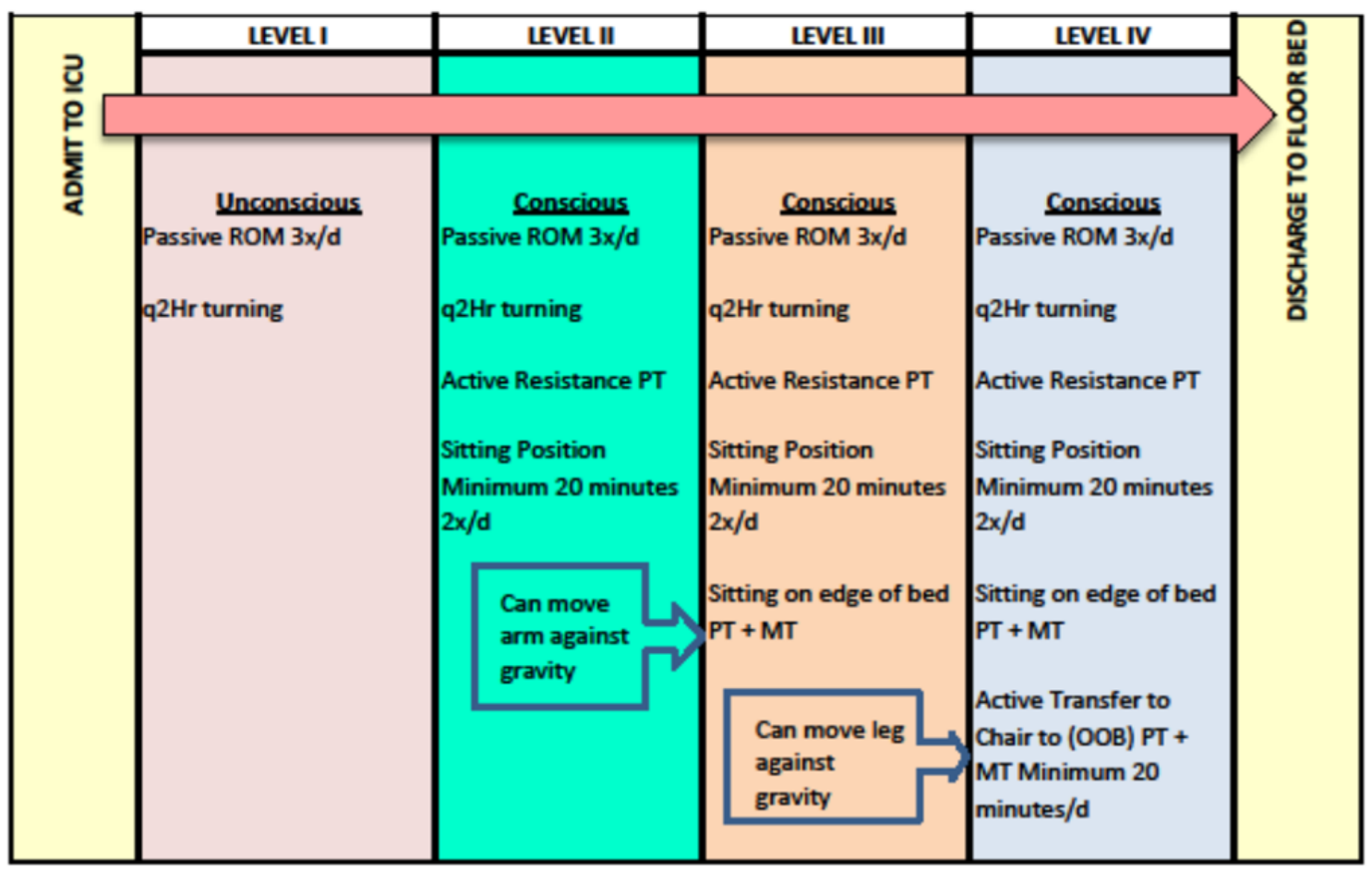

Figure 1. Nurse Driven progressive mobility protocol (Morris et al. 2008).

The nurse manager of the ICU discussed the introduction of a mobility program with staff during the monthly staff meeting prior to the education. The nurse manager asked that the education be incorporated into the annual critical care competency fair. Recruitment included IRB approved flyers (Appendix B) that were posted to encourage participation.

After IRB approval and recruitment activity, nurses were provided an IRB approved informational letter (Appendix C), which was attached to the sealed box labeled Mobility Questionnaires in a main meeting area for nursing staff on the unit. A five question anonymous test (Appendix D) to evaluate knowledge was also provided to nursing staff in a large envelope with the informational letter. Each participant was instructed, via the informational letter, to use a unique identifier known to them but not to the researcher on their pre-test to maintain anonymity. Participants had areas in the ICU 
where completion could be done privately but they could take the test home to complete. The test was voluntary but all staff was encouraged to complete it. The test was used as a guide to the knowledge pre-intervention that would be compared to a test postintervention.

Participants were instructed to use an identifier that they could remember and use on the post-test so research comparisons could be made. Completed surveys were placed in the sealed box and stored in a locked compartment during the study.

The test was multiple choices, based on the literature and discussion on knowledge gaps from the Task Force meetings. It was not pretested but reviewed by nursing faculty advisor.

Intervention. The education was delivered by poster presentation at a station during the annual competency fair for the critical care unit. The education on mobility was determined by the nurse manager to be mandatory for staff employed in the intensive care unit. Poster presentation (Appendix E) outlined the complications of immobility, interventions, exclusions, and the four-step plan for mobility. The author was available for questions and discussion during the fair. Implementation began immediately after the education was completed. Small pocket-sized laminated copy of the mobility continuum was distributed to staff.

In collaboration with the medical staff, nursing, and physical therapy, the nursedriven early mobility protocol was implemented in December 2012, the week following the competency fair, with daily reports on patient's mobility status during interdisciplinary rounds. Nurse champions on each shift were sought to assist with 
recruiting and promoting use of the protocol. Three or four nurses were informally recruited on the basis of their interest and enthusiasm for the new initiative. The researcher reinforced the protocol through periodic reminders and observation of staff. This phase was guided by Lewin's refreezing the change to make it permanent.

About four weeks post implementation of the protocol; nursing again received an informational letter (Appendix F) in the same manner as pre-education as well as the post test (Appendix D). Nursing knowledge and use of the protocol was again evaluated by posttest approximately 4 weeks post implementation of the protocol. In addition to the five questions included in the pre-test, a sixth question was asked regarding to what degree nurses felt they provided earlier mobility to their patients.

\section{Data Analysis}

Descriptive statistics were used to analyze study variables and differences between pre and post scores. 


\section{Results}

Of the 56 eligible ICU nurses, 46 attended the competency fair over the three-day period that it was offered. All were RNs with education spanning from two year ADN graduates to Masters prepared nurses. Experience ranged from new graduates to greater than 40 years of nursing practice. Approximately 25\% had 1-5 years' experience; approximately $30 \%$ had $>25$ years, with about $45 \%$ falling in the $5-25$ year range.

Fifteen nurses volunteered to take the pre-test but only ten of the participants followed the directions to place an identifier in the upper right hand corner for comparison on the post-test. The five tests without the identifier were discarded. The post-test was offered approximately four weeks after implementation of the program. Eight nurses chose to participate in the post-test. Again, two did not use the unique identifier on the post-test, so six tests were available for paired comparisons.

Table 2 on the next page represents the differences between pre- and post-test results on questions one and two, which asked the frequency of repositioning and range of motion performed in the last shift worked, respectively. These first two questions demonstrated that one staff member reported an increase in number of times patients' were repositioned and number of times range of motion was performed. 
Table 2.

Differences Between Pre-test and Post-test Results

\begin{tabular}{|r|c|c|c|}
\hline & Decreased & Stayed the Same & Increased \\
\hline $\begin{array}{r}\text { Question 1 } \\
\text { Repositioning } \\
\text { \#times/shift }\end{array}$ & 0 & 5 & 1 \\
\hline $\begin{array}{r}\text { Question 2 } \\
\text { Range of Motion } \\
\text { Performed }\end{array}$ & 0 & 5 & 1 \\
\#times/shift & & & \\
\hline
\end{tabular}

Table 3 displays responses to three general mobility knowledge questions related to assessing for readiness, best practices for early mobility, and main causes of functional limitations one year after discharge.

\section{Table 3.}

Mobility Knowledge Responses

\begin{tabular}{|r|c|c|c|c|}
\hline & $\begin{array}{r}\text { Pretest } \\
\text { Correct }\end{array}$ & $\%$ & $\begin{array}{c}\text { Post-test } \\
\text { Correct }\end{array}$ & $\%$ \\
\hline $\begin{array}{r}\text { Question 3- When to } \\
\text { assess for readiness }\end{array}$ & $2 / 6$ & $33.3 \%$ & $5 / 6$ & $83.3 \%$ \\
\hline $\begin{array}{r}\text { Question 4- best practice } \\
\text { to facilitate delivery of } \\
\text { EM }\end{array}$ & $1 / 6$ & $16.6 \%$ & $6 / 6$ & $100 \%$ \\
\hline $\begin{array}{r}\text { Question 5- main cause } \\
\text { of functional limits 1 } \\
\text { year after D/C }\end{array}$ & $3 / 6$ & $50 \%$ & $4 / 6$ & $66.6 \%$ \\
\hline
\end{tabular}

As can be seen from Table 3, all three participants demonstrated improvement in knowledge on each of the three questions. 
Table 4 demonstrates nurses' responses regarding the degree to which that they reported that they have provided earlier mobility. This question was only asked on the posttest, so a comparison could not be made.

Table 4.

Degree You Have Provided Earlier Mobility

\begin{tabular}{|r|c|c|c|c|c|}
\hline & $\begin{array}{c}\text { Very } \\
\text { Frequently }\end{array}$ & Frequently & Occasionally & Rarely & Never \\
\hline $\begin{array}{r}\text { Question 6 } \\
\text { Provided Earlier } \\
\text { Mobility }\end{array}$ & 0 & 5 & 1 & 0 & 0 \\
\hline
\end{tabular}

Five nurses answered that they provided earlier mobility frequently and one nurse indicated occasionally.

Mobility practices post-test mainly remained the same as nurses reported frequency of turning and repositioning. One nurse for each question reported increasing frequency of these tasks. Knowledge levels improved slightly when compared to the pretest.

Now, summary and conclusions of this project will be discussed. 


\section{Summary and Conclusions}

Critically ill patients are subjected to long periods of immobility, which often results in prolonged ventilation time, an increase in incidences of pneumonia, pressure ulcers, muscle atrophy, general deconditioning, and falls. These morbidities lead to increased length of stay in the ICU and the hospital as well as functional decline, and many survivors complain of weakness for months to years after discharge from the hospital (Brower, 2009).

Early mobility can lead to positives outcomes including minimizing complications of bed rest, promoting improved function for patients, promoting weaning from ventilator as overall strength and endurance improve, reducing LOS, reducing overall cost, and improving quality of life (Perme \& Chandrashekar, 2009). Barriers and resistance to mobility are present in the ICU. Knowledge, attitudes, and beliefs of ICU staff are a strong precursor to the establishment of ICU culture and define practice patterns. Clinician's knowledge deficits and resistance to change can be barriers to changes in practice, demonstrating resistive forces. Altering well-established routines and patterns of care require a comprehensive approach to instituting not only individual behavior changes but also system wide changes. Some barriers to early mobility may include lack of education on the complications of mobility, excessive sedation, delirium, multiple invasive devices, time constraints, resistance to change, morbid obesity, and lack of specific protocols (Hopkins \& Spuhler, 2009). A nurse-driven progressive mobility protocol allows for safe progression of patient mobility decreasing complications. 
Research has demonstrated that mobility protocols can be implemented into critical care areas safely and effectively.

The purpose of this program development was to increase critical care nurses' understanding of the concept and benefits of early mobility. The literature clearly supported that a standardized approach to mobilizing critically ill patients was essential to improve mobility and overall patient outcomes. The project was an initiative to integrate the latest evidence on mobility practice into current ICU practice. Prior to the initiation of the project, several informal discussion groups within the ICU identified a need for earlier mobility of patients. The inter-disciplinary team, during daily rounds in the ICU, began discussing the need for earlier mobility for improved patient outcomes. This discussion was carried over to the ICU nursing staff meetings. In response to a growing concern from the medical team and nursing clinical managers regarding the need for improved mobility practices, a hospital-wide Mobility Task Force was established.

A nurse-driven progressive mobility protocol developed by Morris et al. (2008) was introduced during an educational program. Development of the program was guided by Lewin's change theory (Lewin, 1951). Prior to implementation, approvals were obtained from the RIC IRB as well as the institutional IRB and administrators. Additions to the protocol were instituted to target the specific teams involved, such as adding the lift team utilized by the ICU in the study. Nursing staff were asked to voluntarily complete a short pre-test about early mobility prior to the educational intervention. The education was delivered in the form of a poster presentation at the annual competency fair for critical care. Implementation of the protocol was initiated after completion of the 
educational program. Mobility was addressed daily during interdisciplinary rounds as nursing staff integrated mobility into their daily care routines. Laminated cards displaying the protocol were distributed for easy reference. Informal support/encouragement was available by the researcher and nurse champions during the implementation. A post-test was administered approximately one month post-education.

Knowledge levels improved slightly when compared to the pretest. An additional question was added to the post test where staff was asked to what degree they felt they were providing earlier mobility to their patients; $83 \%(n=5)$ responded frequently while $17 \%(n=1)$ responded occasionally. However, no comparison could be made due to the fact that this question was only asked on the post-test.

Several limitations of this project are acknowledged. Due to time limitations, the pre-test was only available to staff for five days; this delay impacted the number of staff able to complete the pre-tests $(n=15)$ prior to the education program. Another limitation was that the researcher was asked by the nurse manager to present the educational intervention during the competency fair, which was prescheduled, and time restricted.

The post-test return rate was low $(n=6)$ and analysis was further limited by missing identifiers on many of the post- tests. The low return rate post intervention may have been attributed to several factors, including the one month post intervention time period and lack of an incentive. Limited demographic data was collected from participants, and limited pre and post test questions were used overall due to the time restriction; further study is indicated. While there was some improvement in knowledge, it is possible that more improvement would have been realized if a more traditional, less 
time restricted educational approach had been possible. Also, a follow up intervention with the use of a more 'hands-on' approach may have been beneficial. The challenge of transferring the actual knowledge gained to real practice change is further acknowledged.

In a hospital mobility program, funding must be available for nurse education, lift teams, and new technology such as for lift devices. An interdisciplinary approach must be utilized to ensure patient safety and improved outcomes. With the general aging of our population and increased use of ICU level of care, new and innovative programs must be implemented to assure positive outcomes in populations of patients that are critically ill. In the geriatric population, hospital acquired conditions such as falls, delirium and pressure ulcers can be directly related to immobility. Adverse events from bed rest in the elderly are particularly detrimental because of co-existing age-related changes in muscles, leading to more rapid and prolonged deterioration (Winkelman).

It is hoped that actual mobility in the ICU will increase and that outcomes related to length of stay in the ICU and hospital LOS will show decrease. Anecdotally it appeared to this author that mobility in the ICU had increased; long term support and follow up is indicated. Since the hospital is implementing a hospital wide mobility program concurrent with the ICU program, maintaining mobility throughout a patient's entire hospital stay has the potential to become a reality.

In conclusion, nurses are a key component of mobility initiatives and advanced practice nurses (APRN) are critical is the design, implementation, and evaluation of mobility protocols. The need for organizational system support, resources, continuing 
education for staff, and innovative technology to implement and document these activities are critical elements as well.

Next, recommendations and implications will be discussed. 


\section{Recommendations and Implications for Advanced Nursing Practice}

The Clinical Nurse Specialist (CNS), regardless of practice setting, must always be alert to the need for maintaining or improving the quality of care for his/her patients, families, groups, or communities. It is important for the advanced practice nurse to maintain organizational involvement to be able to understand the priorities within the clinical unit and the overall system. Once a need is identified, a detailed and methodical approach should be utilized to establish the current evidence base, set a goal for future practice, and create a plan for how to achieve this change. The CNS uses evidence-based practice, critically analyze information, and develop, implement, and evaluate initiatives to improve the quality of care. A critical component of any planned project for change is the choice of optimal intervention strategies. The CNS, as project leader, is primarily responsible for the outcome of the project, and any resulting impact on patient care (Fulton, 2010). The CNS guides the health care team in understanding new protocols, educates, and advocates for needed policy change and resources.

The CNSs' work is incorporated into the three spheres of influence: patients, nursing practice, and organization/system, including the development of clinical inquiry skills among staff nurses. The CNS as a change agent must consider the impact on all three spheres of influence. The CNS-driven, interdisciplinary approach to this project was aimed to empower the nurses to realize the potential impact they could have on improving patient outcomes. It was also key to assist the nurses to embrace the organization's vision of change toward early mobility throughout the institution. Further 
research related to mobility is indicated; a key question is how much ambulation is optimal for each patient.

Outcome measures have become a primary focus in health care related to hospital reimbursement rates and penalties. Practitioners at all levels are being challenged to demonstrate that the care delivered will lead to improved patient outcomes and will also prevent hospital-acquired conditions. The CNS is specifically linked to improving nurse sensitive outcomes. Early mobility is a key intervention that can improve nurse-sensitive outcomes, such as pressure ulcers, fall rates and hospital acquired conditions and decrease cost to the patient and institution. The CNS also has a key role in primary prevention and population health; implementing mobility as a routine part of care in health care institutions provides innumerable opportunities to improve the health of the public overall.

The expertise of the CNS can be invaluable in policy development on a local and national level. Participation in professional organizations to improve quality care is an essential part of the role of the CNS. As a specialist, the CNS is invaluable in bringing the latest professional practice guidelines and contributing to practice standard development and guiding nurse sensitive measures. The CNS is an integral part of the interdisciplinary team, giving nursing a voice with expertise on patient care. The CNS, with specialty area expertise, can integrate advanced knowledge on change theory, evidence-based practice, knowledge of the organizational system, and quality improvement indicators to improve patient care throughout the system. 


\section{References}

Adler, J. \& Malone, D. (2012). Early mobilization in the intensive care unit: A systematic review. Cardiopulmonary Physical Therapy Journal, 23(1), 5-13.

Agency for Healthcare Research and Quality. AHRQ Innovations Exchange. March 30, 2009. Available at http://innovations.ahrq.gov. Accessed April 20, 2013.

Allen, C., Glasziou, P., \& DelMar, C. (1999). Bed rest: A potentially harmful treatment needing more careful evaluation. Lancet, 354(9186), 1229-33.

Asher, R. A. (1947). Dangers of going to bed. British Medical Journal, 13(2), 967.

Bailey, P., Thomsen, G. E., Spuhler, V. J., Blair, R., Jewkes, J., Bezdjian, L.,...Hopkins, R. O. (2007). Early activity is feasible and safe in respiratory failure patients. Critical Care Medicine, 35(1), 139-145.

doi:10.1097/01.CCM.0000251130.69568.87

Bassett, R. D., Vollman, K. M., Brandwene, L., \& Murray, T. (2012). Integrating a multidisciplinary mobility programme into intensive care practice (IMMPTP): A multicentre collaborative. Intensive and Critical Care Nursing, 28(28), 88-97. doi:10.1016/j.iccn.2011.12.001

Bjork, I. T., \& Kirkevold, M. (2000). From simplicity to complexity: Developing a model of practical skill performance in nursing. Journal of Clinical Nursing, 9, 620-631.

Brower, R. G. (2009). Consequences of bed rest. Critical Care Medicine, 37(10), S422S428. 
Butcher, W. (2012). Mobility matters, get up off that bed: Evidence-based practice and technology to improve mobility and outcomes of surgical intensive care patients. Critical Care Nurse, 32(2), e50-e51.

Charlson, M. E., Pompei, P., Ales, K. L., MacKenzie, C. R. (1987). A new method of classifying prognostic comorbidity in longitudinal studies: Development and validation. Journal of Chronic Diseases, 40(5), 373-383.

Choi, J., Tasota, F. J., \& Hoffman, L. A. (2008). Mobility interventions to improve outcomes in patients undergoing prolonged mechanical ventilation: a review of the literature. Biological Research for Nursing, 10(1), 21-33.

doi:10.1177/1099800408319055

Clark, D.E., Lowman, J. D., Griffin, R. L., Matthews, H. M., Reiff, D. A. (2013). Effectiveness of an early mobilization protocol in a trauma and burns intensive care unit: A retrospective cohort study. Physical Therapy, 93(2), 186-196.

Drolet, A., DeJuilio, P., Harkless, S., Henricks, S., Kamin, E., Leddy, E. A.,...Williams, S. (2013). Move to improve: The feasibility of using an early mobility protocol to increase ambulation in the intensive and intermediate care settings. Physical Therapy, 93(2), 197-207.

Fitzgibbon, L. (2012). Let's get moving: An interdisciplinary approach to early mobility in the medical intensive care unit. Critical Care Nurse, 32(2), e48.

Gerrish, K., McDonnell, A., Nolan, M., Guillaume, L., Kirshbaum, M., \& Todd, A. (2011). The role of advanced practice nurses in knowledge brokering as a means 
of promoting evidence-based practice among clinical nurses. Journal of Advanced Nursing, 67(9), 2004-2014.

Goldhill, D. R., Imhoff, M., McLean, B., \& Waldmann, C. (2007). Rotational bed therapy to prevent and treat respiratory complications: A review and meta-analysis. American Journal of Critical Care, 16(1), 50-62.

Hopkins, R. O., \& Spuhler, V. J. (2009). Strategies for promoting early activity in critically ill mechanically ventilated patients. AACN Advanced Critical Care, 20(3), 277-289.

Kritsonis, A. (2005). Comparison of change theories. International Journal of Scholarly Academic Intellectual Diversity, 8(1).

Lewin, K. (1951). Field theory in social science. New York: Harper and Brothers.

Lusardi, P. (2012). So you want to change practice: Recognizing practice issues and channeling those ideas. Critical Care Nurse, 32(2), 55-63.

McEwen, M., \& Wills, E. (2007). Theoretical basis for nursing (2nd ed.). Philadelphia, PA: Lippincott, Williams and Wilkins.

Milbrandt, E. B. (2008). Use it or lose it! Critical Care Medicine, 36, 2444-2445. doi:10.1097/CCM.0b013e3181811211

Morris, P. E., Goad, A., Thompson, C., Taylor, K., Harry, B., Passmore, L.,...Haponik, E. (2008). Early intensive care unit mobility therapy in the treatment of acute respiratory failure. Critical Care Medicine, 36, 2238-2243.

doi:10.1097/CCM.0b013e318180b90e 
Morris, P. E., Griffin, L., Berry, M., Thompson, C., Hite, D., Winkelman, C.,...Haponik, E. (2011). Receiving early mobility during and ICU admission is a predictor of improved outcomes in acute respiratory failure. American Journal of Medical Science, 341(5), 373-377. doi:10.1097

Mundy, L. M., Leet, T. L., Darst, K., Schnitzler, M. A., Dunagan, W. C. (2003). Early mobilization of patients hospitalized with community-acquired pneumonia. Chest, 124(3), 883-9.

Overton, G. K., McCalister, P., Kelly, D., \& Macvicar, R. (2009). Practice-based small group learning: How health professionals view their intention to change and the process of implementing change in practice. Medical Teacher, 31(11), e514-e519.

Perme, C., \& Chandrashekar, R. (2009). Early mobility and walking program for patients in intensive care units: creating a standard of care. American Journal of Critical Care, 18(3), 212-220. doi: 10.4037/ajcc2009598

Paratz, J., Kayambu, G. (2011). Early exercise and attenuation of myopathy in the patient with sepsis in ICU. Physical Therapy Reviews 16 (1), 58-65.

Ross, A.G., Morris, P. E. (2010). Safety and barriers to care. Critical Care Nurse, 30(2), S11-13.

Schweickert, W.D.,Pohlman, M.C., Pohlman, A.S., Nios, C., Pawlik, A.J., Esbrook, C.L.,...Kress, J.P. (2009). Early physical and occupational therapy in mechanically ventilated, critically ill patients: A randomized controlled trail. Lancet, 373(9678), 1874-82. 
Timmerman, R. A. (2007). A mobility protocol for critically ill adults. Dimensions in Critical Care Nursing, 26(5), 175-179.

Tran, D. T., Stone, A. M., Fernandez, R. S., Griffiths, R. D., \& Johnson, M. (2009). Does implementation of clinical practice guidelines change nurses' screening for alcohol and other substance abuse? Contemporary Nurse, 33(1), 13-19.

Vollman, K. (2009). Back to the fundamentals of care: Why now, why us! Australian College of Critical Care Nurses, 22, 152-154. doi:10.1016/j.aucc.2009.09.001

Vollman, K. M. (2010). Progressive mobility in the critically ill. Critical Care Nurse, 30(2), S3-S5.

Winkelman, C. (2009). Bed rest in health and critical illness. AACN Advanced Critical Care, 20(3), 254-266.

Winkelman, C., \& Peereboom, K. (2010). Staff-perceived barriers and facilitators. Critical Care Nurse, 30(2), S13-S16

University of Wisconsin-Extension Program Development and Evaluation. (n.d.). Logic model. Retrieved from http://www.uwex.edu/pdande/evaluation/evaldocs.html 


\section{Appendix A}

Logic Model

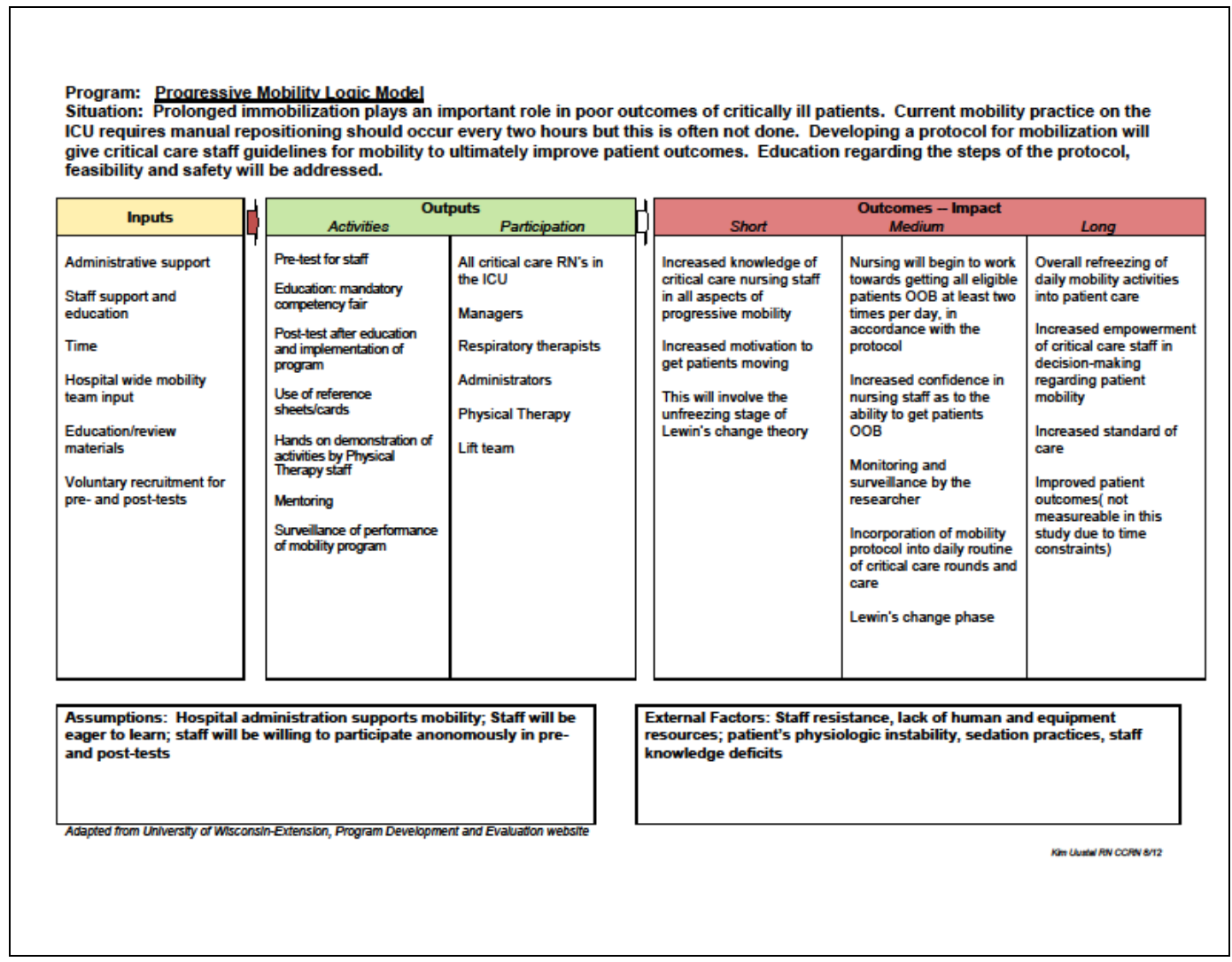


Appendix B

Recruitment Flyer 


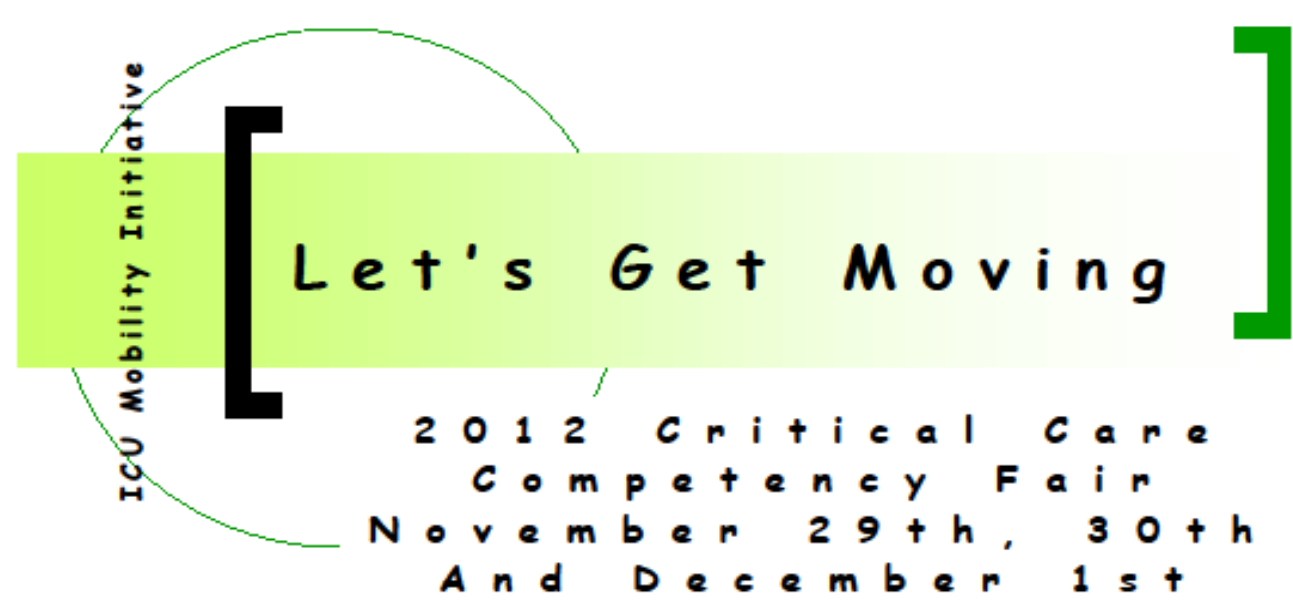

\section{Nurse-driven Progressive Mobility \\ Protocol is coming to ICU!}

Education about early mobility will be part of our annual competency fair at the end of November.

As part of my Masters project, I am recruiting staff members to take part in a voluntary 5-6 question survey pre- and post-implementation. The pre/post survey is to assess understanding about early mobility.

The survey will be completely anonymous.

Please help me by participating. If you have any questions, please contact me.

Thank you.,

Kim Uustal RN

Intensive Care Unit 3-11 PM

401-742-6585

Rhode Island College Institutional Review Board

Wood/Uustal study

Approval \#: 1213-22

Expiration Date: $11 / 2 / 2013$

Kuustal@KentRI.org 
Appendix C

Informational Letter 
Dear ICU nursing staff,

You are being invited to participate in a study. I will be conducting a pre- and post-educational survey surrounding nurse knowledge in regards to patient mobility in critical care. An educational program about a nurse-driven progressive mobility protocol will be presented in our annual critical care competency fair at the end of November. The survey is voluntary and will be kept anonymous. The survey consists of 5-6 questions. If you decide to take the survey, please select a code word that will not reveal your identity and mark it in a space in the upper right hand corner. Please remember this identifier for use when you complete the post-survey so that information can be compared. Participation in the survey will assume consent was obtained. You are encouraged to respond to all questions but may choose not to complete any or all of the questions. Your decision to participate or not to participate will not impact your position in any way. Completed surveys can be deposited in this sealed box

There are no direct benefits to your participation and there are no identified risks to participating. The pre and post surveys will be kept private, stored in a locked file, accessible only by the student researcher and faculty advisor. You will not be identified in any way. If you have any questions, please feel free to contact me. If you complete the survey, then you are agreeing to participate in the study.

Thank you for your consideration of this request.

Kim Uustal RN

Kuustal@KentRI.org

401-742-6585

Rhode Island College, Candidate for Master of Nursing

Wood/Uustal study Version $11 / 24 / 2012$
Rhode Island College Institutional Review Board Approval \#: 1213-31 Expiration Date: 11/24/2013
Page 1 of 1 


\section{Appendix D}

Pre- and Post-Tests

1) In your last shift, how many times did you turn and reposition your patient?
a) Once
b) Twice
c) Every 2 hours
d) Not at all

2) In your last shift, was range of motion performed and if so, how many times?

e) Once

f) Twice

g) Never

h) More than 2 times

3) When should ICU patients be assessed for readiness for mobility?
a) Within 48 hours of admission and daily
b) After extubation, if awake
c) Each time a patient's condition changes significantly
d) At the time of initiation of progressive mobility protocol

4) Evidence-based practices to facilitate daily delivery of early ICU mobility include best practices in which of the following areas?

a) Management of sedatives and analgesics, promotion of sleep for ICU patients

b) Using physical therapists to initiate progressive mobility protocols, prioritization of procedures by ICU nurses

c) Physician ordered "out of bed" activity; staff education regarding the complications associated with bed rest and immobility

d) Use of beds that allow for patients to be positioned with backrest, hips and knees angles at 90 degrees, protocols that include daily passive range of motion 
5) What is the main cause of functional limitations occurring in patients within 1 year after discharge from the ICU?
a) Heart muscle deconditioning
b) Skin breakdown/delayed wound healing
c) Joint contractures
d) Muscle wasting

Question \#6 to be on the post-survey for the researcher's information:

To what degree do you feel you have provided earlier mobility to your patients?
a) Very frequently
b) Frequently
c) Occasionally
d) Rarely
e) Never 
Appendix E

Poster Presentation 

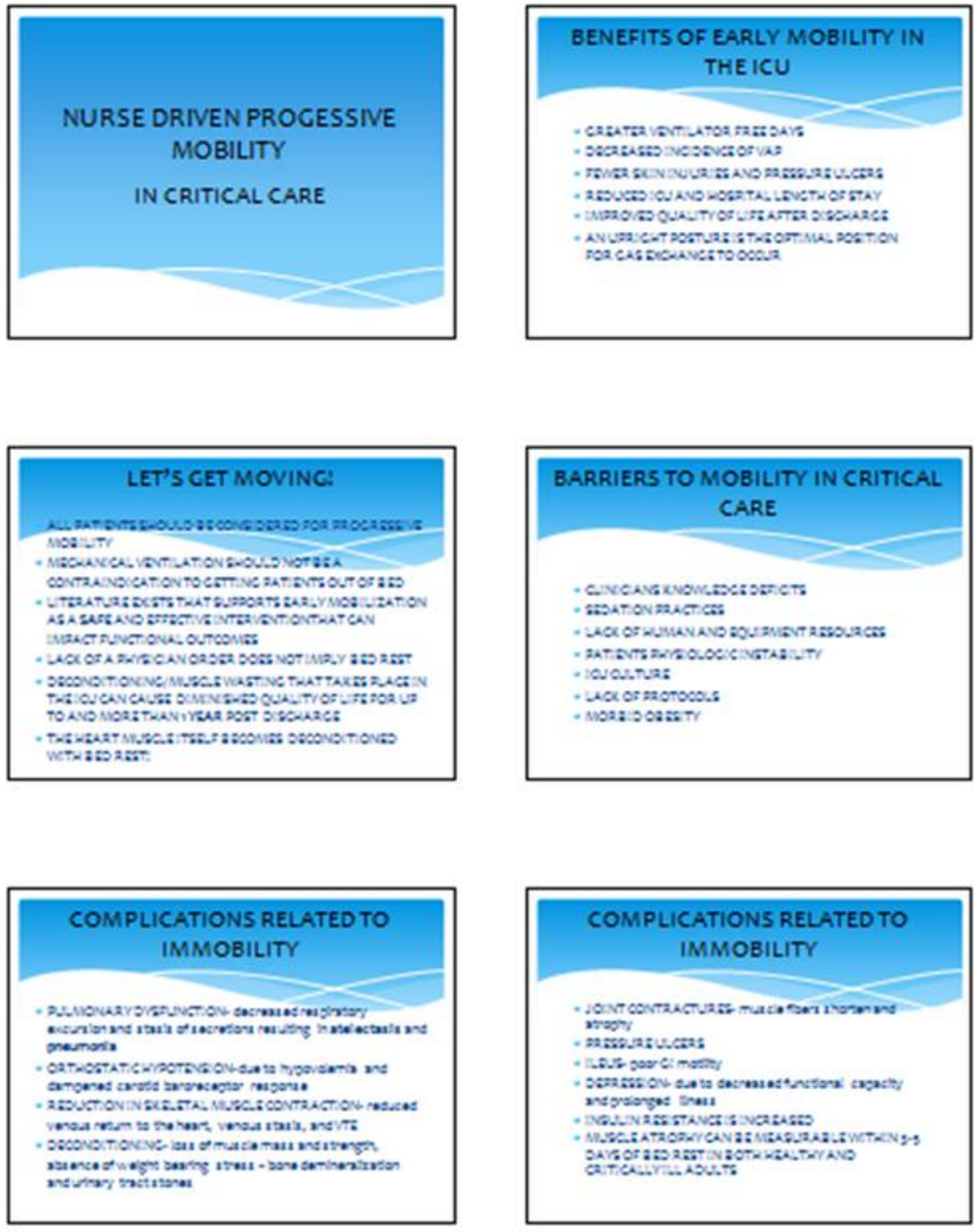

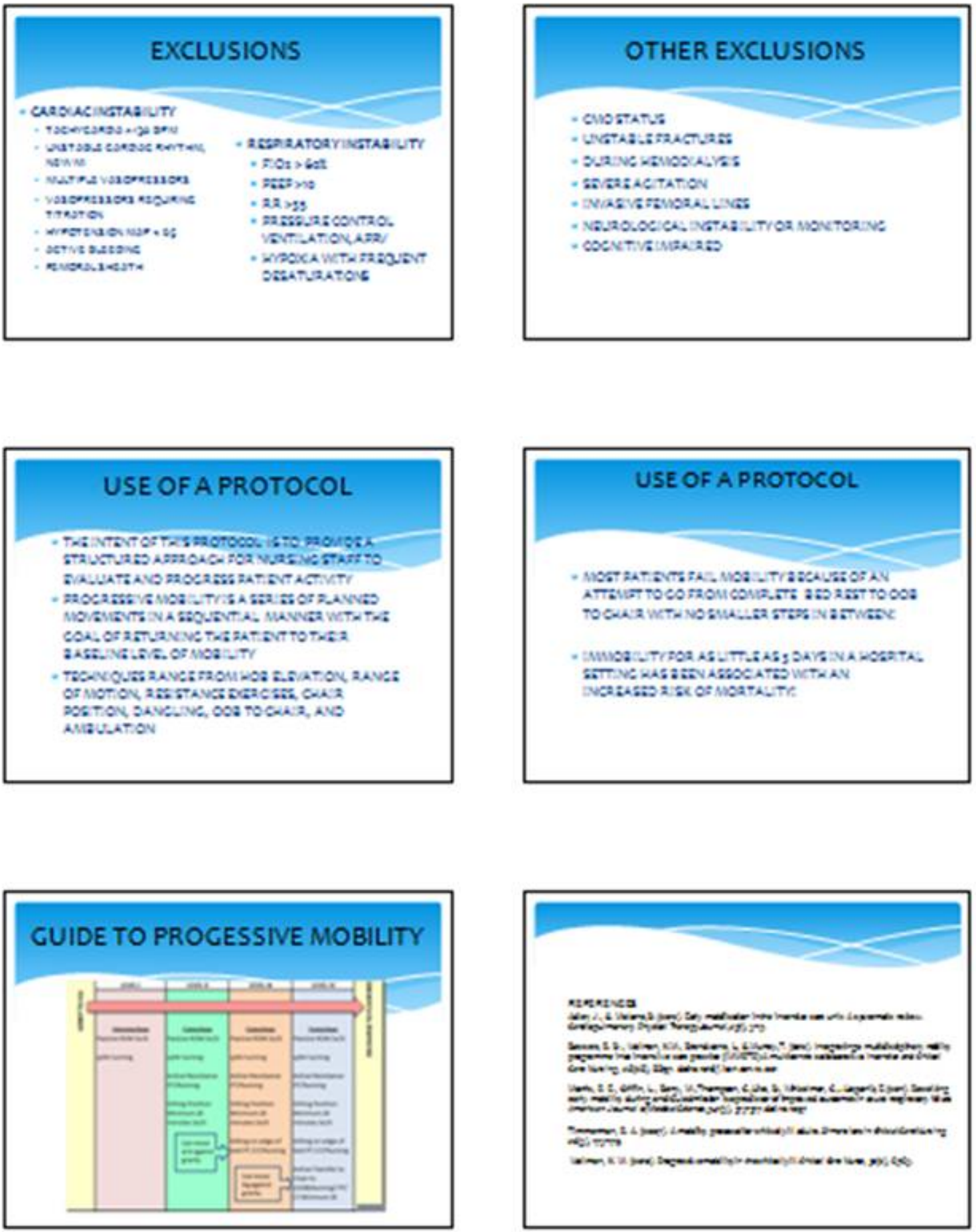
Appendix F

Post-test Informational Letter 


\section{Dear ICU Nursing Staff,}

Thank you for your participation in the implementation of the nurse-driven mobility protocol for ICU. Please take this 6 question post-test. It will remain anonymous. You should use the unique identifier that you chose in the pre-test on the top of your test. Completed forms can be deposited in this sealed box. You are encouraged to respond to all questions but may choose not to complete any or all of the questions. Your decision to participate or not to participate will not impact your position in any way.

There are no direct benefits to your participation and there are no identified risks to participating. The pre and posttests will be kept private, stored in a locked file, accessible only by the student researcher and faculty advisor. You will not be identified in any way. If you have any questions, please feel free to contact me. If you complete the test, then you are agreeing to participate in the study.

Thank you for your consideration of this request.

\section{Kim Uustal RN}

Kuustal@,KentRI.org

401-742-6585

Rhode Island College, Candidate for Master of Nursing 